\title{
DESENVOLVIMENTO DE DIGESTOR ANAERÓBIO DIDÁTICO E TESTES DE PRODUÇÃO DE BIOGÁS COM RESÍDUOS DA BOVINOCULTURA E CAFEICULTURA
}

\section{Daniel Pereira Muniz TEPERINO ${ }^{1}$, Manoel Antônio LADEIRA Neto ${ }^{2}$, Adriano Henrique FERRAREZ ${ }^{*}$, Anders Teixeira GOMES², Henrique Santos Poubel $^{2}$ \& Elias dos Santos da SILVA ${ }^{2}$}

1Universidade Federal de Viçosa. Viçosa, Minas Gerais, Brasil.

2Instituto Federal de Educação, Ciência e Tecnologia Fluminense, campus Itaperuna. Itaperuna, Rio de Janeiro, Brasil. *Autor para correspondência: aferrarez@iff.edu.br

DOI: http://dx.doi.org/10.18571/acbm.140

\section{RESUMO}

As indústrias desde o século XIX têm utilizado os combustíveis fósseis em larga escala. A queima desses combustíveis libera uma grande quantidade de gases que aumenta a capacidade da atmosfera de reter calor, consequentemente, gerando problemas como chuva ácida e o agravamento do efeito estufa. O biogás obtido da digestão anaeróbia de dejetos animais, resíduos agrícolas, industriais ou residenciais é uma alternativa energética para a humanidade. Considerando-se que a energia está presente em todas as ações da nossa sociedade, a educação energética tem grande importância nos dias atuais. O objetivo deste trabalho foi a construção de digestor anaeróbio didático e a realização de testes de produção de biogás com resíduos da cafeicultura e bovinocultura da região Noroeste Fluminense. Os Digestores Anaeróbios Didáticos (DAD) foram construídos com materiais de baixo custo como tubo de PVC e garrafas PET. O carregamento dos DAD foi realizado com concentrações determinadas (v/v) dos substratos e volume total de $250 \mathrm{~mL}$. A produção de biogás foi registrada diariamente medindo-se o deslocamento vertical da coluna de líquido em cada DAD. Os dados obtidos evidenciaram a produção de biogás em três dos cinco digestores, com incremento da produção de biogás ao longo do tempo. Concluiu-se que o DAD cumpriu o objetivo de demonstrar didaticamente a produção de biogás. $\mathrm{O}$ equipamento foi considerado seguro e de fácil operação, podendo ser utilizado para popularizar o uso do biogás como fonte de energia renovável.

Palavras-Chave: Codigestão anaeróbia; Energia renovável; Sustentabilidade.

\begin{abstract}
Industries since the 19th century have used fossil fuels on a large scale. The burning of these fuels releases a large amount of gases that increases the atmosphere's ability to retain heat, hence generating problems such as acid rain and worsening of the greenhouse effect. Biogas obtained from the anaerobic digestion of animal waste, agricultural, industrial or residential wastes is an energetic alternative for humanity. Considering that energy is present in all actions of our society, energetic education has great importance in the present day. The objective of this work was to construct a didactic anaerobic digester and test biogas production with coffee and cattle residues from the Noroeste Fluminense region. Anaerobic Didactic Digesters (DAD) were built with low cost materials such as PVC pipe and PET bottles. DAD loading was performed with determined concentrations $(\mathrm{v} / \mathrm{v})$ of the substrates and total volume of $250 \mathrm{~mL}$. Biogas production was recorded daily by measuring the vertical displacement of the liquid column in each DAD. The data obtained evidenced the biogas production in three of the five digesters, with an increase in biogas production along the time. It was concluded that the DAD met the objective of demonstrating biogas production. The didactic anaerobic digester was considered safe and easy to operate, and could be used to popularize the use of biogas as a source of renewable energy.
\end{abstract}

Keywords: Anaerobic codigestion; Renewable Energy; Sustainability. 


\section{Introdução}

O século XIX e, principalmente, o século XX foram marcados pelas maiores revoluções industriais ocorridas no planeta. Esse desenvolvimento foi possível graças a um grande consumo de energia. Para movimentar as fábricas foram utilizadas grandes quantidades de combustíveis fósseis. Essa energia não renovável e poluente foi evoluindo desde o carvão mineral até o petróleo, atualmente o combustível mais utilizado no mundo para obtenção de energia (FARIAS e SELLITTO, 2011).

A queima de combustíveis fósseis libera uma grande quantidade de gases - vapor de água $\left(\mathrm{H}_{2} \mathrm{O}\right)$, clorofluorcarbono $(\mathrm{CFC})$, ozônio $\left(\mathrm{O}_{3}\right)$, metano $\left(\mathrm{CH}_{4}\right)$, óxido nitroso $\left(\mathrm{N}_{2} \mathrm{O}\right)$ e o dióxido de carbono $\left(\mathrm{CO}_{2}\right)$ - que aumenta a capacidade da atmosfera de reter calor, consequentemente, gerando problemas como chuva ácida e o agravamento do efeito estufa. Esses gases absorvem uma parte da radiação infravermelha que a superfície da Terra emite e, posteriormente, irradiam uma parte dessa energia de volta para a superfície terrestre (SILVA e PAULA, 2009).

Além do aquecimento global e chuva ácida, os combustíveis fósseis também se encaixam entre as principais causas da poluição atmosférica urbana e da degradação das regiões costeiras. Isso ocorre porque a maioria da frota automotiva do mundo é formada por veículos impulsionados através da queima de combustíveis que despejam grande quantidade de dióxido de carbono $\left(\mathrm{CO}_{2}\right)$ e monóxido de carbono (CO) no ar (GOLDEMBERG e LUCON, 2008).

O problema causado pelos gases provenientes da queima de combustíveis fósseis é tão grande que se tornou um assunto discutido a nível mundial, ocorrendo diversos encontros e congressos para esse fim. Entre essas reuniões se destacam: (i) Conferência Eco-92, realizada na cidade do Rio de Janeiro no Brasil em 1992; (ii) Conferência das Partes - COP 3, realizada na cidade de Quioto no Japão em 1997; (iii) Conferência Rio+20 também realizada no Rio de Janeiro em 2012; e (iv) Conferência das Partes (COP 21) na cidade de Paris na França em 2016, ocasião em que se aprovou o Acordo do Clima. Na COP 21 de Paris um total de 195 países aprovaram medidas para a redução das emissões de gases do efeito estufa (GEE). Dentre as principais medidas para a diminuição das emissões de GEE está a redução do uso de combustíveis fósseis (MORGAN, 2016).

Devido à enorme quantidade de problemas gerados pelos combustíveis fósseis e/ou qualquer outra forma de energia não renovável, tem-se buscado formas de melhorar os métodos de aquisição energética visando também a preservação ambiental. A busca por um desenvolvimento sustentável, a iniciativa de gerar energia através de resíduos e/ou dejetos orgânicos surge com grande força para a transformação do sistema energético.

Nesse cenário o biogás obtido da digestão anaeróbia de dejetos animais, resíduos agrícolas, industriais ou residenciais é uma alternativa energética para a humanidade. Como recurso energético renovável a tecnologia do biogás contribui para a redução das emissões de GEE e a poluição atmosférica (POESCHL et al., 2010). Embora o conhecimento do biogás pela humanidade remonte ao século XVII, essa forma de energia ainda é desconhecida da grande maioria das pessoas. Para que ocorra o desenvolvimento do setor do biogás no Brasil é necessária sua popularização.

\subsection{Resíduos Agropecuários}

Os resíduos agropecuários podem ser de origem animal (dejetos de bovinos, suínos, aves, etc) ou vegetal (resíduos dos cultivos agrícolas). Esses resíduos constituem um grave problema ambiental provocando a poluição de rios e águas subterrâneas com compostos como amônia, nitratos e outros elementos tóxicos, além da disseminação de patógenos.

A agropecuária da região Noroeste Fluminense contribui com $12 \%$ do PIB produzido pelo setor no Estado do Rio de Janeiro (FIRJAN, 2015). 
Os principais cultivos agrícolas e rebanhos pecuários da região Noroeste Fluminense são mostrados nas Tabelas 1 e 2 .

Tabela 1: Principais cultivos agrícolas da região Noroeste Fluminense.

\begin{tabular}{lll}
\hline Cultivos agrícolas & Produção anual (t) & $\begin{array}{l}\text { \% Produção do Estado do } \\
\text { Rio de Janeiro }\end{array}$ \\
\hline Arroz & 1.993 & 69,73 \\
Café & 10.895 & 62,32 \\
Milho & 5.197 & 46,98 \\
Tomate & 82.915 & 39,97 \\
\hline Fonte: (IBGE $2016 \mathrm{a})$ & &
\end{tabular}

Fonte: (IBGE, 2016a)

Tabela 2: Principais rebanhos pecuários da região Noroeste Fluminense.

\begin{tabular}{lll}
\hline Rebanhos pecuários & Número de cabeças & $\begin{array}{l}\text { \% Rebanho do Estado do } \\
\text { Rio de Janeiro }\end{array}$ \\
\hline Bovino & 510.961 & 21,47 \\
Caprino & 5.851 & 24,99 \\
Ovino & 4.669 & 10,91 \\
Suíno & 24.037 & 23,23 \\
\hline
\end{tabular}

Fonte: (IBGE, 2016b).

Buscar soluções tecnológicas sustentáveis é uma necessidade para promover o desenvolvimento socioeconômico da região Noroeste Fluminense.

O aproveitamento energético dos resíduos agropecuários é uma alternativa para mitigar os impactos ambientais da atividade. Um dos possíveis processos de conversão desses dejetos em energia é a codigestão anaeróbia (HILLS e ROBERTS, 1981; HASHIMOTO, 1983).

\subsection{Digestão, codigestão anaeróbia e biogás}

A degradação de matéria orgânica sem a presença de oxigênio caracteriza a digestão anaeróbia. No primeiro estágio do processo as bactérias fermentativas hidrolisam e fermentam as matérias orgânicas mais complexas (carboidratos, proteínas e lipídios) transformando-os em ácidos graxos, álcool, dióxido de carbono, hidrogênio, amônia e sulfetos. No segundo estágio as bactérias acetogênicas consomem os produtos primários produzindo hidrogênio, dióxido de carbono e ácido acético. No terceiro estágio as bactérias metanogênicas reduzem o dióxido de carbono a metano e descarboxila o ácido acético produzindo metano e dióxido de carbono, respectivamente (SALMINEM e RINTALA, 2002).

A Figura 1 mostra as fases da digestão anaeróbia.

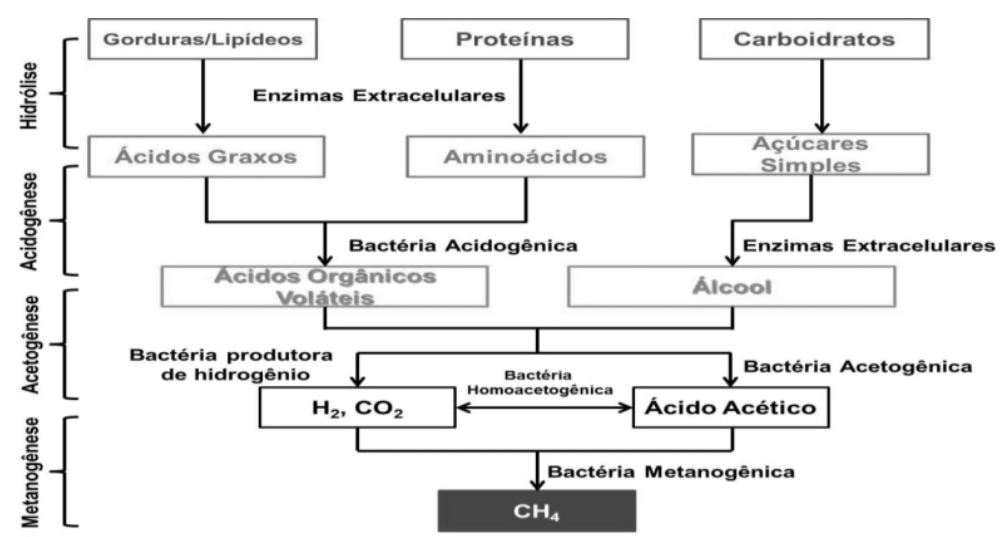

Figura 1: Esquema da digestão anaeróbia. Adaptado de (AL SEADI, 2001). 
Na digestão anaeróbia é utilizado apenas um substrato. Quando dois ou mais substratos são utilizados o processo de degradação da matéria orgânica recebe o nome de codigestão anaeróbia.

A codigestão é um processo de digestão anaeróbica conjunta entre dois ou mais substratos orgânicos, sendo que devem estar dentro do mesmo biodigestor. A codigestão é a mescla de resíduos orgânicos, geralmente unindo dejetos animais a resíduos vegetais, para melhorar o rendimento da digestão anaeróbica, visto que a combinação de materiais de origem animal e vegetal aumenta a relação carbono/nitrogênio $(\mathrm{C} / \mathrm{N})$ do substrato e ao mesmo tempo fornece mais nutrientes para as bactérias metanogênicas se manterem vivas (MATA-ALVAREZ et al., 2000).

A codigestão apresenta algumas vantagens em relação à técnica que utiliza apenas um substrato degradável tais como: (i) aumento da produção de biogás; (ii) manutenção do pH ótimo para as bactérias metanogênicas; (ii) diminuição da amônia livre que é um inibidor da produção de biometano; (iii) diminuição da demanda bioquímica de oxigênio (DBO); (iv) equilíbrio de nutrientes, devido à variedade de substratos, contribuindo para a estabilidade da digestão e resultando num digestato com maior potencial fertilizante; (v) redução de custos e o uso eficiente de equipamentos uma vez que centraliza o processamento de vários resíduos em um mesmo local; (vi) manejo da mistura de resíduos, o uso de instalações comuns para o tratamento de diferentes resíduos e os efeitos da economia de escala (XIE et al., 2011; ORRICO JÚNIOR et al., 2010; ÁLVAREZ et al., 2010; LANSING, et al., 2010).

O produto proveniente da digestão e codigestão anaeróbia de resíduos orgânicos é o biogás cuja produção é extremamente sustentável e vantajosa. O biogás pode ser purificado sendo então chamado de biometano atingindo conteúdo energético semelhante ao do gás natural. A Tabela 3 mostra a composição típica dos principais gases constituintes do biogás.

Tabela 3: Composição da mistura gasosa do biogás.

\begin{tabular}{ll}
\hline Gases & Porcentagem \\
\hline Metano $\left(\mathrm{CH}_{4}\right)$ & $55-70$ \\
Dióxido de Carbono $\left(\mathrm{CO}_{2}\right)$ & $30-45$ \\
Hidrogênio $\left(\mathrm{H}_{2}\right)$ & $1-3$ \\
Nitrogênio $\left(\mathrm{N}_{2}\right)$ & $0,5-2,5$ \\
Oxigênio $\left(\mathrm{O}_{2}\right)$ & $0,1-1$ \\
Ácido Sulfídrico $\left(\mathrm{H}_{2} \mathrm{~S}\right)$ & $0,1-0,5$ \\
Amônia $\left(\mathrm{NH}_{3}\right)$ & $0,1-0,5$ \\
Monóxido de Carbono $(\mathrm{CO})$ & $0-0,1$ \\
Água $\left(\mathrm{H}_{2} \mathrm{O}\right)$ & Variável \\
\hline Fonte: $(\mathrm{DEUBLEIN} \mathrm{e} \mathrm{STEINHAUSER,} \mathrm{2011).}$
\end{tabular}

\subsection{Viabilidade da produção de biogás}

A produção de biogás demanda a disponibilidade de material orgânico biodegradável e isso não é problema para o Brasil (um país agroexportador) e muito menos para a região investigada a região noroeste fluminense, visto que a atividade econômica se concentra essencialmente no campo, com a bovinocultura, suinocultura, plantações de café, arroz e milho.

Pode-se afirmar que o Brasil apresenta forte tendência para o setor primário, em especial o setor agropecuário como mostram as pesquisas realizadas pelo Centro de Estudos Avançados em Economia Aplicada que registra no setor agropecuário um percentual de cerca de 21,46\% do Produto Interno Bruto Total do país no ano de 2015. Comparativamente a países desenvolvidos, é uma participação elevada desse setor econômico no PIB nacional (CEPEA, 2015).

O Brasil apresenta vantagens para a produção de biogás como a grande produção de resíduos originados da agropecuária brasileira. Outra vantagem é a oportunidade de mitigação do aquecimento global que seria um incentivo para o financiamento de projetos relacionados a área de energias renováveis (GENOVESE et al., 2006). 


\subsection{Digestores Anaeróbios}

Os biodigestores são câmaras que realizam a fermentação anaeróbia da matéria orgânica que consiste na transformação de compostos orgânicos complexos em metano e dióxido de carbono por meio da ação de microrganismos que atuam na ausência de oxigênio. A escolha adequada do biodigestor é fundamental para o desenvolvimento apropriado do processo da biodigestão anaeróbia, estando diretamente relacionada com a produção de biogás (STEINSBERGER e SHIH, 1984).

\subsubsection{Biodigestor: Modelo da Marinha}

Esse modelo de biodigestor é montado horizontalmente e apresenta uma cúpula de plástico, geralmente em material PVC, que se enche à medida que a mistura gasosa chega até ela. Tem como vantagem a grande exposição à luz solar, fazendo com que haja uma maior produção de biogás devido ao aquecimento. Apresenta como vantagens: (i) baixo custo de instalação; (ii) flexibilidade em ser colocado na superfície ou no subsolo; (iii) fácil conservação e limpeza. Como desvantagens podem ser elencadas: (i) tempo de vida útil curto (5 anos); (ii) manutenção constante; e (iii) sensibilidade a mudanças de temperatura (ANDRADE et al., 2002).

\subsubsection{Biodigestor: Modelo Chinês}

O biodigestor modelo chinês apresenta uma alimentação de substrato semi-contínua e seu reator de fermentação localiza-se no subsolo a fim de minimizar as variações de temperatura. Esse modelo tem forma de cúpula e funciona com os princípios de prensa hidráulica, ou seja, quanto mais gás produzido, maior a pressão dentro do digestor fazendo com os dejetos sejam empurrados para a área de saída. É construído em alvenaria com a câmara de fermentação abobadada e impermeável com a finalidade de armazenar o biogás produzido. Dentre as desvantagens do modelo chinês está o fato que devido a problemas na construção em alvenaria e a grande variação de pressão dentro do biodigestor podem ocorre vazamentos (FLORENTINO, 2003).

\subsubsection{Biodigestor: Modelo Indiano}

O modelo indiano possui uma campânula metálica para armazenar o gás produzido, essa campânula flutua sobre os dejetos utilizados ou sobre um selo d'água. Essa peça do sistema pode ficar abaixo do substrato ou imersa em lâmina de água para que sejam diminuídas as perdas por vazamento. Esse tipo de biodigestor trabalha com pressão constante porque o gasômetro se desloca à medida que recebe o biogás produzido e requer uma alimentação contínua. Dentre as desvantagens desse modelo estão o custo de construção do digestor e a vida útil curta devido a corrosão do gasômetro de metal (DEGANUTTI et al., 2002; ANDRADE, et al., 2002).

\subsection{Educação energética e ambiental}

A energia está presente em todas as nossas ações. A disponibilidade, qualidade e custo da energia precisam ser considerados em todos os projetos do nosso dia a dia, desde um simples planejamento de férias até um plano de governo para vários anos de investimentos. Energia é cada vez mais a questão central nos dias atuais e próximos. O acesso à energia é algo estruturante na nossa sociedade. É de interesse público que os cidadãos tenham esse direito. Existe a indissociabilidade entre energia e desenvolvimento, mas a dinâmica desse relacionamento resulta em forte pressão sobre o meio ambiente, uma vez que o crescimento econômico tem estado atrelado à expansão da oferta de energia. Verifica-se nos últimos tempos o surgimento de uma 
consciência ambiental o que implica numa maior preocupação com a sustentabilidade energética. Infelizmente essa não é uma preocupação geral da população, nem da maioria dos setores produtivos e políticos (MACEDO, 2016).

A educação energética e ambiental deveria fazer parte da formação de todo brasileiro, fornecendo conhecimento da "matriz" de fontes/usos de energia, com informação quantitativa sobre as fontes primárias de energia usadas (petróleo, hidráulica, biomassa, nuclear, etc) sua conversão para formas de energia mais úteis para o uso final (eletricidade, calor, acionamento mecânico, iluminação), as perdas e desperdícios associados, e sua distribuição pelos setores de uso (residencial, industrial, comercial, transportes, etc). Parte dessa formação envolveria introduzir os princípios da termodinâmica, o entendimento das conversões de energia, evolução, causas e consequências do uso da energia, o fim da era do petróleo e aquecimento global.

Este trabalho teve como objetivo desenvolver um digestor anaeróbio didático e realizar testes de produção de biogás através dos resíduos da cafeicultura e bovinocultura da região Noroeste Fluminense. O presente trabalho foi realizado no Laboratório de Energias Renováveis (LABER) do Instituto Federal de Educação, Ciência e Tecnologia Fluminense campus ItaperunaRJ.

\section{Material e Métodos}

\subsection{Construção dos Digestores Anaeróbios Didáticos}

Os Digestores Anaeróbios Didáticos (DAD) foram construídos com materiais de baixo custo, apresentados na Tabela 4.

Tabela 4: Material utilizado para a construção de um Digestor Anaeróbio Didático (DAD).

\begin{tabular}{lcc}
\hline Material & Quantidade & Unidade \\
\hline Tubo de PVC de $75 \mathrm{~mm}$ & 50 & $\mathrm{~cm}$ \\
Cap de PVC de $75 \mathrm{~mm}$ & 2 & un. \\
Tubo de válvula de Câmara de ar & 2 & un. \\
Garrafa Pet de 3 litros & 1 & un. \\
Mangueira de Silicone & 1 & $\mathrm{~m}$ \\
\hline
\end{tabular}

A garrafa PET foi utilizada como reservatório dos resíduos (digestor), ou seja, onde ocorre a digestão anaeróbia da matéria orgânica. O cano PVC lacrado pelos "caps" funcionou como o gasômetro, local no qual o biogás foi armazenado. A mangueira de silicone e as válvulas são usadas como conectores entre o digestor (garrafa PET) e o gasômetro (tubo PVC).

Para a realização deste trabalho foram construídos cinco Digestores Anaeróbicos Didáticos (DAD) denominados: DAD B1, DAD B2. DAD B3, DAD B4 e DAD B5.

\subsection{Montagem e Carregamento dos biodigestores anaeróbios didáticos}

Os cinco Digestores Didáticos Anaeróbicos (DAD) foram montados em suportes. A matéria orgânica em cada um dos biodigestores foi composta por um inóculo que desempenha um papel importante para iniciar a digestão anaeróbia. $\mathrm{O}$ inóculo equilibra as populações de bactérias e aceleram o processo principalmente em materiais difíceis de serem digeridos (PALHARES, 2005; SHAH, et al., 2014). O início do processo de digestão anaeróbia é fundamental, pois uma inicialização com falhas pode comprometer todo o processo. Problemas na partida no processo implicam na ineficiência na remoção de matéria orgânica do substrato (HEYDT, et al., 2015).

O inóculo utilizado neste trabalho foi o subproduto final do processo de biodigestão de resíduos da bovinocultura (dejetos de bovinos) recolhidos em um matadouro do município de 


\section{Biomedica Brasiliensia}

Itaperuna e resíduos de café (palha da pós-colheita) obtidas de uma propriedade rural da região Noroeste Fluminense.

Os substratos foram preparados para a realização da digestão úmida, ou seja, com teor de matéria seca no digestor igual ou inferior a $12 \%$.

O carregamento dos Digestores Anaeróbios Didáticos (DAD) ocorreu de acordo com os percentuais da concentração (v/v) de cada substrato orgânico nos respectivos DAD sendo o volume total igual a $250 \mathrm{ml}$ para cada um, conforme mostrado pela Tabela 5.

Tabela 5: Concentração (v/v) de substratos nos DAD.

\begin{tabular}{llll}
\multicolumn{4}{l}{ Concentração dos Substratos (v/v) } \\
\hline DAD B1 & $30 \%$ inoculo & $70 \%$ dejetos bovinos & - \\
DAD B2 & $30 \%$ inoculo & $70 \%$ resíduos cafeicultura & - \\
DAD B3 & $30 \%$ inoculo & $35 \%$ dejetos bovinos & $35 \%$ resíduos cafeicultura \\
DAD B4 & $30 \%$ inoculo & $52,5 \%$ dejetos bovinos & $17,5 \%$ resíduos cafeicultura \\
DAD B5 & $30 \%$ inoculo & $52,5 \%$ resíduos cafeicultura & $17,5 \%$ dejetos bovinos \\
\hline
\end{tabular}

\subsection{Quantificação da Produção de Biogás}

Para quantificar a produção de biogás realizou-se a leitura diária do deslocamento vertical da coluna de líquido em cada DAD, durante a leitura diária foi realizada também a agitação manual do digestor (Figura 2).

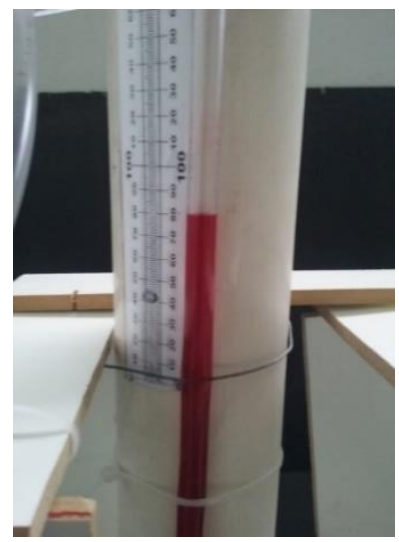

Figura 2: Deslocamento da coluna de líquido na lateral do DAD.

O deslocamento da coluna de líquido é proporcional ao volume do biogás produzido. A partir da medição do deslocamento da coluna de líquido, conhecendo-se o raio da mangueira de silicone é possível calcular-se o volume de biogás produzido cujo cálculo foi realizado a partir da equação (1) a seguir.

$$
V=\pi \cdot r^{2} \cdot h
$$

em que:

$$
\begin{array}{lll}
\mathrm{V} & \text { - volume de biogás produzido, } & \mathrm{cm} 3 \\
\mathrm{r} & - \text { raio da mangueira de silicone, } & \mathrm{cm} \\
\mathrm{h} & - \text { altura da coluna de líquido deslocado, } & \mathrm{cm} .
\end{array}
$$

Realizando-se a correção para condições normais de temperatura e pressão (CNTP) conforme a equação 2 a seguir descrita por Aquino et al. (2007). 


$$
\frac{P_{o} \cdot V_{o}}{T_{o}}=\frac{P_{1} \cdot V_{1}}{T_{1}}
$$

em que:

Po - Pressão corrigida do biogás,

Vo - Volume de biogás corrigido,

To - Temperatura corrigida do biogás,

P1 - Pressão do biogás no instante da leitura,

V1 - Volume do biogás no instante da leitura,

T1 - Temperatura ambiente no instante da leitura, mm de $\mathrm{H} 2 \mathrm{O}$;

$\mathrm{mm} 3$;

$\mathrm{K}$;

mm de $\mathrm{H} 2 \mathrm{O}$;

$\mathrm{mm} 3$;

$\mathrm{K}$.

\section{Resultados e Discussão}

\subsection{Protótipo do Digestor Anaeróbio Didático}

A Figura 3 a mostra o protótipo do Digestor Anaeróbio Didático (DAD) construído a partir deste trabalho. A partir da Figura 3 se observa o digestor anaeróbio (garrafa PET) e o gasômetro montado a partir do tubo e os tampões (cap) de PVC.

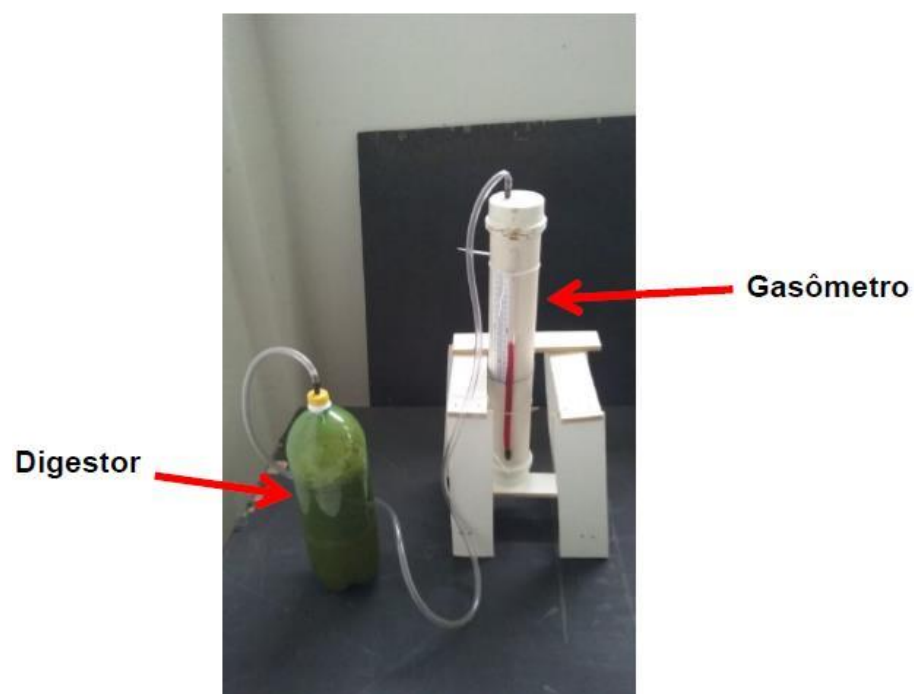

Figura 3: Protótipo do Digestor Anaeróbio Didático (DAD).

\subsection{Montagem do experimento com o Digestor Anaeróbio Didático}

A Figura 4 mostra o experimento montado com os 5 Digestores Anaeróbios Didáticos.

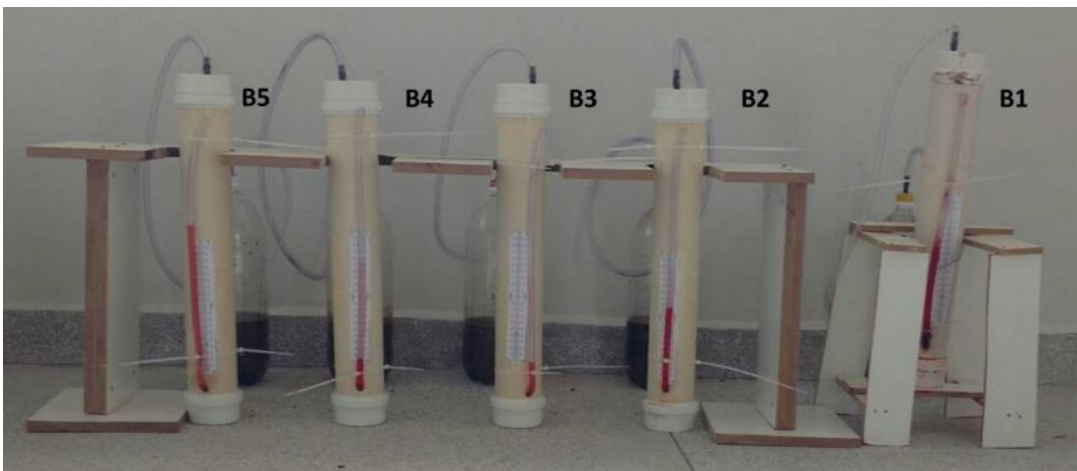

Figura 4: Montagem dos biodigestores. 


\subsection{Temperatura Ambiente}

A temperatura ambiente média durante o período do experimento foi de $25,4{ }^{0} \mathrm{C}$. A menor temperatura ocorreu no $3^{0}$ dia de experimento e a maior no $25^{\circ}$ dia. A amplitude térmica foi de $8,5^{\circ} \mathrm{C}$. Dada a faixa de temperatura em que o ocorreu a digestão anaeróbia dos resíduos pode-se considerar o processo como mesofílico. A Figura 5 mostra as temperaturas registradas durante o período do experimento.

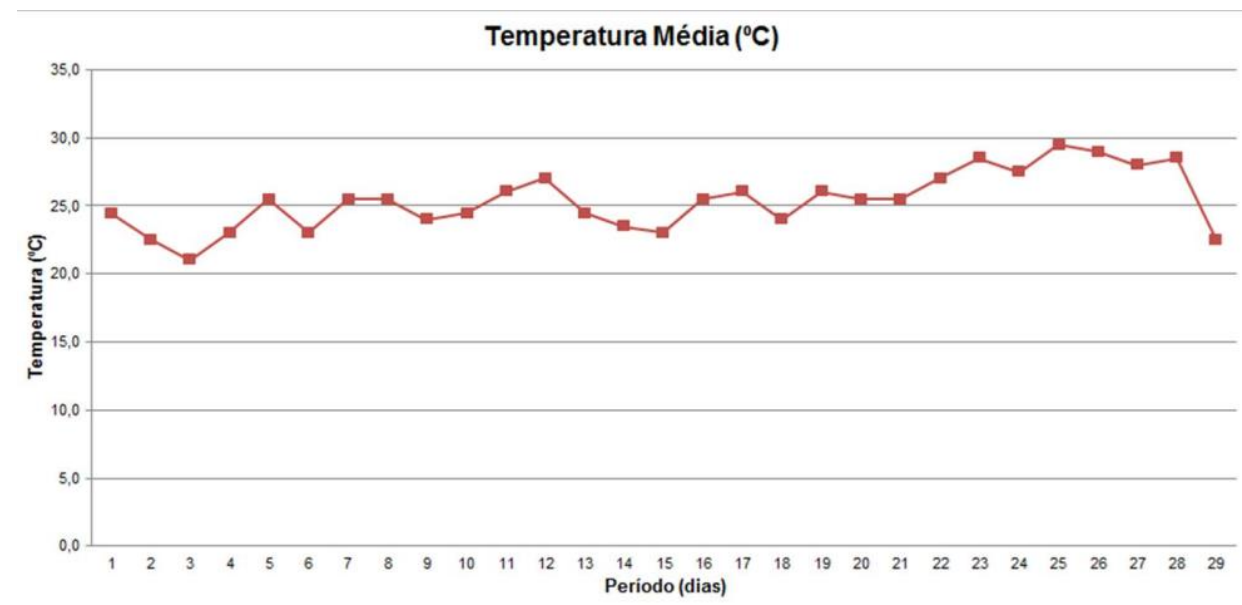

Figura 5: Temperatura ambiente média.

\subsection{Produção de biogás no Digestor Anaeróbio Didático}

A Figura 6 mostra a produção de biogás em função do período (em dias) no DAD B1.

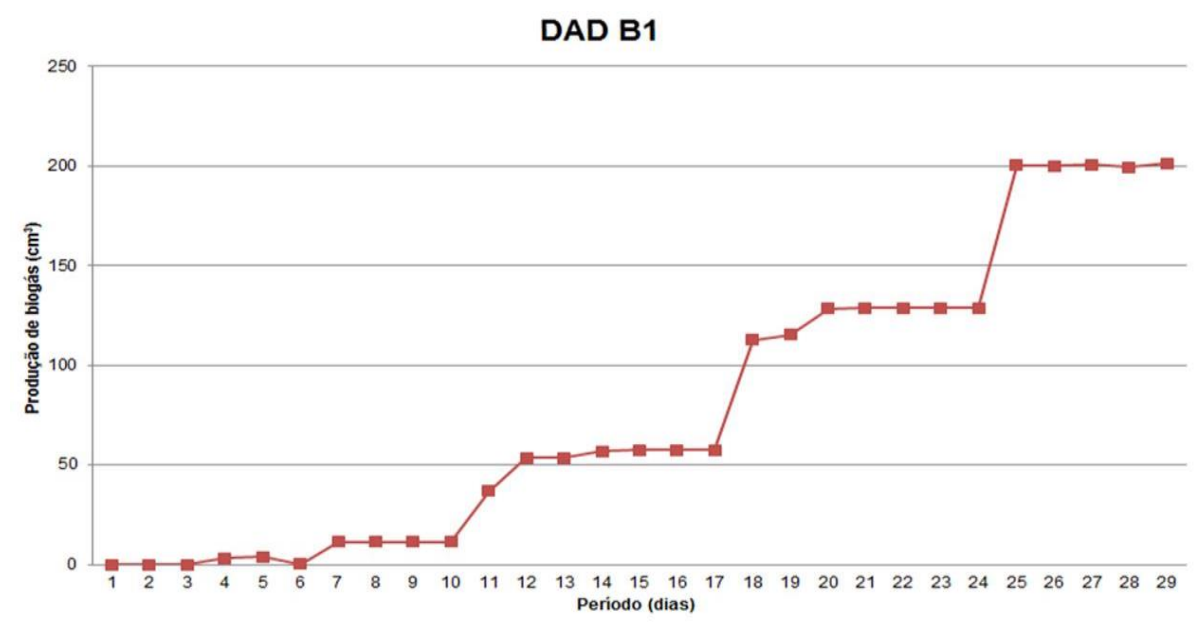

Figura 6: Produção acumulada de biogás no DAD B1.

O DAD B1 foi carregado com 30\% de inóculo e $70 \%$ de dejetos bovinos. Observou-se que o processo de digestão anaeróbia se iniciou efetivamente após o $6^{\circ}$ dia do experimento. A produção acumulada de biogás no DAD B1 após 29 dias foi de 201,34 $\mathrm{cm}^{3}$. Ocorreram 3 grandes picos de produção de biogás sendo eles: $\left(1^{\circ}\right)$ Entre o $10^{\circ}$ e o $12^{\circ}$ dia com uma variação na produção de biogás igual a $\Delta \mathrm{Vi}=42,09 \mathrm{~cm}^{3} ;\left(2^{\circ}\right)$ Entre o $18^{\circ}$ e o $17^{\circ}$ dia com uma variação na produção de biogás igual a $\Delta \mathrm{Vii}=55,35 \mathrm{~cm}^{3}$; e $\left(3^{\circ}\right)$ Entre o $24^{\circ}$ e o $25^{\circ}$ dia com uma variação na produção de biogás igual a $\Delta \mathrm{Viii}=71,74 \mathrm{~cm}^{3}$.

Embora a temperatura seja ao mesmo tempo fator otimizador e inibidor da produção de biogás, não se pode atribuir à variação de temperatura o incremento da produção de biogás nestes 
períodos uma vez que as amplitudes térmicas durante esses picos foram de: (I) $\Delta \mathrm{T} 1=1,5^{\circ} \mathrm{C}$; (II) $\Delta \mathrm{T} 2=-2,0{ }^{\circ} \mathrm{C}$; e (III) $\Delta \mathrm{T} 3=2,0{ }^{\circ} \mathrm{C}$. Não foi possível concluir os motivos desses picos na produção de biogás no DAD B1.

A Figura 7 mostra a produção de biogás em função do período (em dias) no DAD B2.

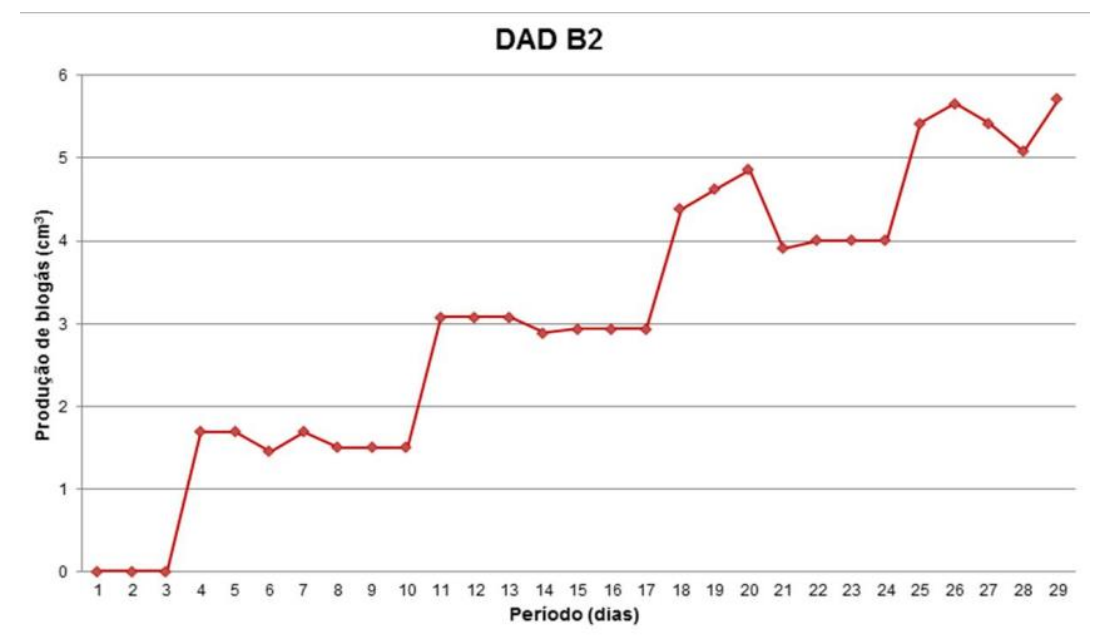

Figura 7: Produção acumulada de biogás no DAD B2.

O DAD B2 foi carregado com 30\% de inóculo e $70 \%$ de resíduos da cafeicultura. Observou-se que o processo de digestão anaeróbia se iniciou efetivamente após o $3^{\circ}$ dia do experimento. A produção acumulada de biogás no DAD B2 após 29 dias foi de $5,71 \mathrm{~cm} 3$. Ocorreram 4 grandes picos de produção de biogás sendo eles: $\left(1^{\circ}\right)$ entre o $3^{\circ}$ e o $4^{\circ}$ dia com uma variação na produção de biogás igual a $\Delta \mathrm{Vi}=1,69 \mathrm{~cm}^{3} ;\left(2^{\circ}\right)$ entre o $10^{\circ}$ e o $11^{\circ}$ dia com uma variação na produção de biogás igual a $\Delta V \mathrm{Vii}=1,58 \mathrm{~cm}^{3} ;\left(3^{\circ}\right)$ entre o $17^{\circ}$ e o $20^{\circ}$ dia com uma variação na produção de biogás igual a $\Delta V$ iii $=1,93 \mathrm{~cm}^{3}$; e $\left(4^{\circ}\right)$ entre o $24^{\circ}$ e o $26^{\circ}$ dia com uma variação na produção de biogás igual a $\Delta \mathrm{Viv}=1,66 \mathrm{~cm}^{3}$. Ocorreram também dois vales, ou decréscimos, na produção de biogás sendo eles: (V) entre o $20^{\circ}$ e $21^{\circ}$ dia com uma variação na produção de biogás igual a $\Delta \mathrm{V} 5=-0,95 \mathrm{~cm}^{3}$; e (VI) entre o $26^{\circ}$ e $28^{\circ}$ dia com uma variação na produção de biogás igual a $\Delta \mathrm{V} 6=-0,58 \mathrm{~cm}^{3}$.

As amplitudes térmicas durante os picos de produção de biogás foram de: (I) $\Delta \mathrm{T} 1=2,0$ ${ }^{0} \mathrm{C}$; (II) $\Delta \mathrm{T} 2=1,5{ }^{\circ} \mathrm{C}$; (III) $\Delta \mathrm{T} 3=-0,5{ }^{\circ} \mathrm{C}$; e (IV) $\Delta \mathrm{T} 4=1,5{ }^{\circ} \mathrm{C}$. As amplitudes térmicas durante os vales de produção de biogás foram de: (V) $\Delta \mathrm{T} 5=0,0{ }^{\circ} \mathrm{C}$; e (VI) $\Delta \mathrm{T} 6=-0,5^{\circ} \mathrm{C}$. A partir destes dados não foi possível concluir os motivos desses picos e vales na produção de biogás no DAD B2.

A Figura 8 mostra a produção de biogás em função do período em dias no DAD B3. 
DAD B3

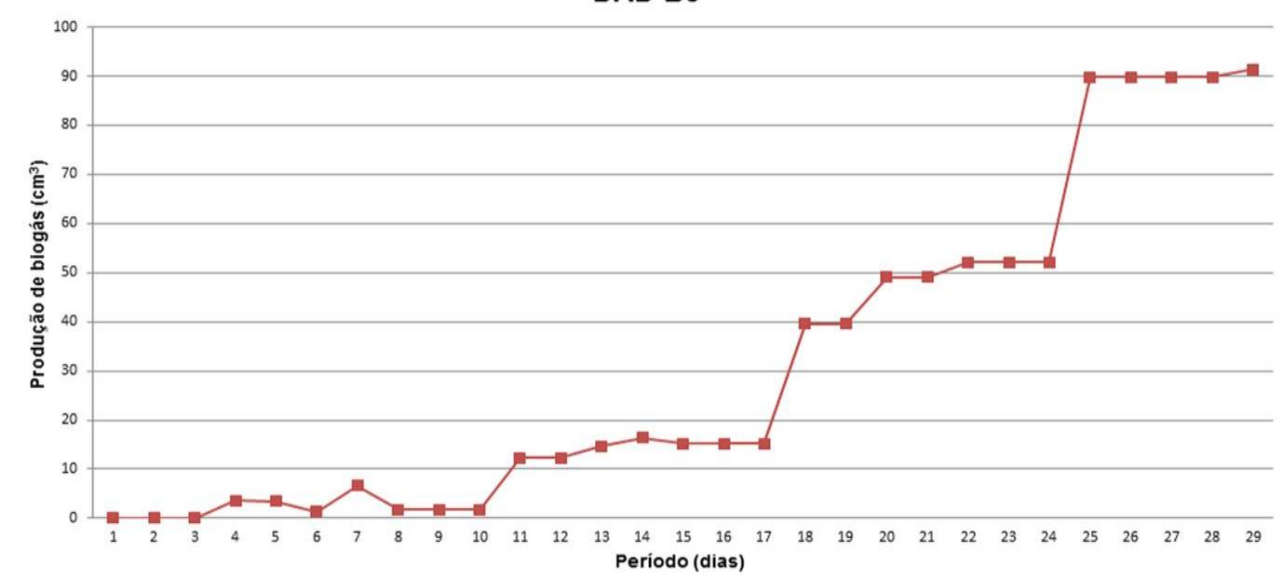

Figura 8: Produção acumulada de biogás no DAD B3.

O DAD B3 foi carregado com 30\% de inóculo, 35\% de dejetos bovinos e 35\% de resíduos da cafeicultura. Observou-se que o processo de digestão anaeróbia se iniciou efetivamente após o $10^{\circ}$ dia do experimento. A produção acumulada de biogás no DAD B3 após 29 dias foi de 91,54 $\mathrm{cm}^{3}$. Ocorreram três grandes picos de produção de biogás sendo eles: $\left(1^{\circ}\right)$ entre o $10^{\circ}$ e o $11^{\circ}$ dia com uma variação na produção de biogás igual a $\Delta \mathrm{V} 1=10,54 \mathrm{~cm}^{3} ;\left(2^{\circ}\right)$ entre o $17^{\circ}$ e o $18^{\circ}$ dia com uma variação na produção de biogás igual a $\Delta V 2=24,35 \mathrm{~cm}^{3}$; e $\left(3^{\circ}\right)$ entre o $24^{\circ}$ e o $25^{\circ}$ dia com uma variação na produção de biogás igual a $\Delta \mathrm{V} 3=37,70 \mathrm{~cm}^{3}$. As amplitudes térmicas foram de: (I) $\Delta \mathrm{T} 1=1,5{ }^{\circ} \mathrm{C}$; (II) $\Delta \mathrm{T} 2=-2,0{ }^{\circ} \mathrm{C}$; e (III) $\Delta \mathrm{T} 3=2,0{ }^{\circ} \mathrm{C}$. Com os dados obtidos não foi possível concluir os motivos desses picos na produção de biogás no DAD B3.

O DAD B4 foi carregado com 30\% de inóculo, 52,5\% de dejetos bovinos e 17,5\% de resíduos da cafeicultura. Alguma condição adversa inibiu o processo de digestão anaeróbia de forma que não ocorreu a produção de biogás no DAD B4.

A Figura 12 mostra a produção de biogás em função do período em dias no DAD B5.

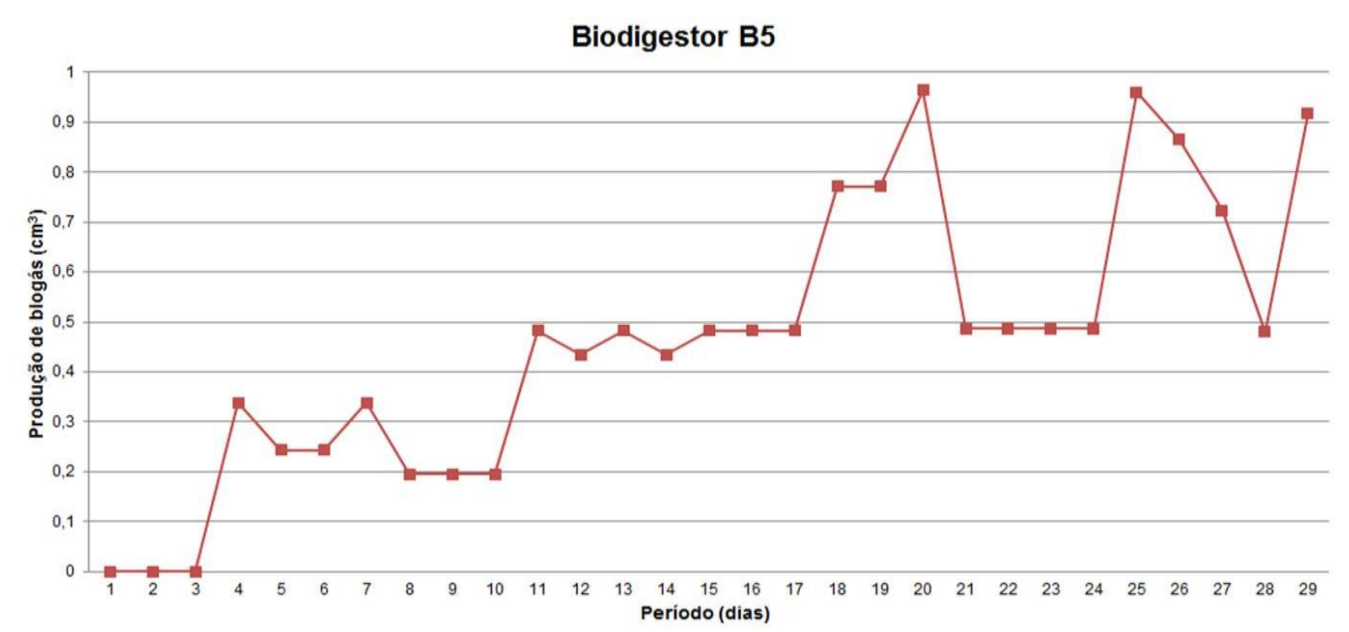

Figura 12: Produção acumulada de biogás no biodigestor B5.

O DAD B5 foi carregado com 30\% de inóculo, 52,5\% de resíduos da cafeicultura e 17,5\% de dejetos bovinos. Observou-se que o processo de digestão anaeróbia se iniciou efetivamente após o $3^{\circ}$ dia do experimento. A produção acumulada de biogás no DAD B3 após 29 dias foi de $0,92 \mathrm{~cm} 3$, ou seja, praticamente nula. Observou-se picos e vales durante todo o experimento, mas sempre com um incremento e decréscimo na produção de biogás muito pequenos. Da mesma forma que no DAD B4 pode-se dizer que alguma condição adversa inibiu o processo de digestão anaeróbia no DAD B5. 
A inibição da atividade metanogênica pode ter sido ocasionada por: (i) pela queda do $\mathrm{pH}$ o que gerou uma quantidade excessiva de ácidos graxos voláteis (HEYDT, et al., 2015); (ii) A variação diária de temperatura afeta significativamente a digestão anaeróbia e a quantidade de biogás produzido. Para que o processo se mantenha estável, a temperatura do substrato no interior do digestor deve ser controlada. A temperatura influencia na taxa de ação bacteriana bem como na umidade do biogás. O teor de umidade do biogás aumenta exponencialmente com a temperatura. A quantidade de gás e a quantidade de substâncias orgânicas dissolvidas na solução, assim como a concentração de amônia e de ácido sulfídrico também são influenciados pela temperatura (BURKE, 2001); (iii) Na Figura 4 pode-se observar que os digestores (garrafas PET) utilizados no experimento eram transparentes. De acordo com Deublein e Steinhauser (2011), a luminosidade é uma condicionante negativa para a digestão anaeróbia.

\section{Conclusão}

O Digestor Anaeróbio Didático (DAD) cumpriu o objetivo de demonstrar didaticamente a produção de biogás a partir dos resíduos agropecuários (dejetos bovinos e resíduos da cafeicultura). O DAD se mostrou um equipamento de baixo custo, seguro e de fácil operação. $\mathrm{O}$ equipamento pode ser utilizado para popularizar o uso do biogás como fonte de energia renovável.

Foi possível quantificar a produção de biogás em três dos cinco DAD carregados e a coleta de dados diárias foi realizada sem maiores contratempos.

Os gráficos da produção de biogás (cm3) em função do tempo (dias) mostrou nos digestores DAD B1, DAD B2 e DAD B3 o processo de incremento da produção de biogás com o passar do tempo.

Não foi possível por meio deste trabalho, concluir o motivo pelo qual o digestor DAD B4 não produziu biogás e o motivo pelo qual o digestor DAD B5 apresentou baixo desempenho.

\section{Referências}

AL SEADI, T. Good practice in quality management of AD residues from biogas production. Report made for the International Energy Agency, Task 24- Energy from Biological Conversion of Organic Waste. Published by IEA Bioenergy and AEA Technology Environment, Oxfordshire, United Kingdom, 2001.

ÁLVAREZ, J.A., OTERO, L., LEMA, J.M. A methodology for optimising feed composition for anaerobic co-digestion of agro-industrial wastes. Bioresource Technology. v. 101, 1153-1158, 2010.

ANDRADE, M. A. N., et al. Biodigestores rurais no contexto da atual crise de energia elétrica brasileira e na perspectiva da sustentabilidade ambiental. Procedings of the 4th Encontro de Energia no Meio Rural, 2002.

BURKE, D. A. Dairy Waste Anaerobic Digestion Handbook. 2001. 57 p. Disponível em: http://www.makingenergy.com/Dairy\%20Waste\%20Handbook.pdf. Acessado em 10 de novembro de 2016

CEPEA. Centro De Estudos Avançados Em Economia Aplicada. PIB do agronegócio, 2012. Disponível em: <http://www.cepea.esalq.usp.br/pib/>. Acessado em 15 de setembro de 2016.

DEGANUTTI, R., PALHACI, M. do C. J. P., ROSSI, M.. Biodigestores rurais: modelo indiano, chinês e batelada.. In: Encontro de energia no meio rural, n. 4, Campinas - SP, 2002. 
DEUBLEIN, D., STEINHAUSER, A. Biogas from waste and renewable resources: an introduction. Second, revised and expanded edition. John Wiley \& Sons, 2011.

FARIAS, L. M.; SELLITTO, M. A. Uso da energia ao longo da história: evolução e perspectivas futuras. Revista Liberato, v. 12, n. 17, p. 01-106, 2011.

FIRJAN. (2015). Retratos Regionais. Disponível em: http://www.firjan.com.br/lumis/portal/file/fileDownload.jsp?fileId=2C908A8F4EBC426A014E CFCDF55C0771\&inline=1. Acessado em 05 de agosto de 2016.

FLORENTINO, H. O. Mathematical tool to size rural digesters. Scientia Agricola, v.60, p.185190, 2003.

FONSECA, F. S. T, et al. Analise de Viabilidade Econômica de Biodigestores na Atividade de Suinocultura na Cidade de Balsas - MA: um Estudo de Caso. In: Congresso da sociedade brasileira de economia, administração e sociologia rural. Universidade Estadual do Maranhão. Maranhão, 2009.

GENOVESE, A. L.; UDAETA, M. E. M.; GALVAO, L. C. R. Aspectos energéticos da biomassa como recurso no Brasil e no mundo. In: Encontro de energia no meio rural, n. 6., Campinas SP, 2006.

GOLDEMBERG, J.; LUCON, O. Energia, meio ambiente e desenvolvimento. 2008.

HASHIMOTO, A.G. Conversion of straw-manure mixtures to methane at mesophilic and thermophilic temperatures. Biotechnology and Bioengineering, v.25, p. 185-200, 1983.

HEYDT, A. R. et al. Biodigestão anaeróbia de resíduos líquidos de fecularia com adição de glicerol em fase termofílica. Revista Gestão \& Sustentabilidade Ambiental, Florianópolis, v. 4, n. esp, p. 498-514, 2015.

HILLS, D.J., ROBERTS, D.W. Anaerobic digestion of dairy manure and field cropresidues. Agricultural Wastes, v. 3: p. 179-189, 1981.

IBGE. (2016a). Pesquisa Agrícola Municipal. Instituto Brasileiro de Geografia e Estatística. Disponível em: http://www.sidra.ibge.gov.br/bda/pesquisas/pam/default.asp?o=29\&i=P, Acessado em 21 de agosto de 2016.

IBGE. (2016b). Pesquisa Pecuária Municipal. Instituto Brasileiro de Geografia e Estatística. Disponível em: http://www.sidra.ibge.gov.br/bda/pesquisas/ppm/default.asp?o=28\&i=P, Acessado em 21 de agosto de 2016.

LANSING, S., MARTIN, F., BOTERO, R.B., NOGUEIRA DA SILVA, T., DIAS DA SILVA, E. Methane production in low-cost, unheated, plug-flow digesters treating swine manure and used cooking grease. Bioresource Technology, v.101, p. 4362-4370, 2010.

MACEDO, I. Energia: fontes e usos finais no Brasil. São Paulo, http://www.comciencia.br/reportagens/2004/12/05.shtml. Acessado em 06 de dezembro de 2016. 
MATA-ALVAREZ, J.; MACE, S.; LLABRES, P. Anaerobic digestion of organic solid wastes. An overview of research achievements and perspectives. Bioresource Technology, v. 74, p. 3-16, ago., 2000.

MORGAN, J. Paris COP 21: Power that speaks the truth?. Globalizations, v. 13, n. 6, p. 943-951, 2016.

ORRICO JUNIOR, M.A.P., ORRICO, A.C.A., LUCAS JUNIOR, J. Biodigestão anaeróbia dos resíduos da produção avícola: cama de frangos e carcaças. Engenharia Agrícola, v. 30, 546-554, 2010.

PALHARES, J. C. P. Uso de biodigestores para o tratamento da cama de frango: conceitos importantes para a produção de biogás. 7 p., 2005 . Disponível em: $<$ http://www.agencia.cnptia.embrapa.br/Repositorio/quali1_000gafw0pal02wx5ok047vs6lgf6sqb t.pdf >. Acessado em: 22 de março de 2017.

POESCHL, M., WARD, S., OWENDE, P. Prospects for expanded utilization of biogas in Germany, Renewable and Sustainable Energy Reviews, v. 14, p. 1782-1797, 2010.

SALMINEN, E., RINTALA, J. Anaerobic digestion of organic solid poultry slaughterhouse waste - a review, Bioresource Technology, v 83, p.13-26, 2002.

SHAH, F. A.; MAHMOOD, Q.; SHAH, M. M.; PERVEZ, A.; ASAD, S. A. Microbial Ecology of Anaerobic Digesters:The Key Players of Anaerobiosis. International Journal of Chemical Engineering, v. 2014, p.21, 2014.

SILVA, R. W. C.; PAULA, B. L. Causa do aquecimento global: antropogênica versus natural. Terræ Didatica, v. 5, p. 42-49, 2009.

STEINSBERGER, S. C., SHIH, J. C. The construction and operation of a low-cost poultry waste digesters. Biotechnology and Bioengineering, v.26, p. 537-543, 1984.

XIE, S., LAWLOR, P.G., FROST, J.P., HU, Z., ZHAN, X. Effect of pig manure to grass silage ratio on methane production in batch anaerobic co-digestion of pig manure and grass silage. Bioresource Technology, v.102, p. 5728-5733, 2011. 